\title{
Case series: Bladder clot evacuation using a prostate morcellation device
}

\author{
Karen M. Doersch, MD'; Andrew F. Navetta, MD'; Erin T. Bird, MD'; Marawan M. El Tayeb, MD'2 \\ 'Department of Microbial Pathogenesis and Immunology, Texas A\&M Health Science Centre College of Medicine; ${ }^{2}$ Division of Urology, Baylor Scott and White Health; Temple, TX, United States
}

Cite as: Can Urol Assoc J 2017;11 (7):E31 1-4. http://dx.doi.org/10.5489/cuaj.4219

Published online July 11, 2017

\section{Abstract}

Introduction: We sought to provide a technical update on the use of a prostate morcellator device (PMD) to manage organized blood clots of the bladder following laser prostatectomy.

Methods: Herein, we describe our experience in using the Wolf Piranha morcellator in managing organized bladder blood clots supplemented with a retrospective chart review of the patients in whom this procedure was performed.

Results: Six patients, all male with a mean age of $75 \pm 8.9$ years, had organized bladder clots following either holmium laser enucleation or photoselective vaporization of the prostate managed with a PMD. Clots were recognized based on hematuria or urinary retention a median of 3.5 days following the aforementioned procedures. Initial management was attempted with more conservative measures, including a three-way Foley catheter, followed by cystoscopy with an Ellik evacuator, or a glass Tommey syringe. Morcellation times were a mean of $10.2 \pm 6.15$ minutes (range $2-18$ ). This technique was able to manage clots that were an average of $173.3 \pm 115.9 \mathrm{cc}$ in size. The procedure was well-tolerated. No patients experienced intraoperative or morcellator-related complications.

Conclusions: Benign prostatic hypertrophy frequently requires surgical endoscopic management and can be complicated by hematuria and bladder blood clot formation. When these clots become organized, this can lead to urinary retention and the required management, evacuation, may be difficult. The use of a Wolf Piranha PMD is a safe, well-tolerated, and effective in evacuating organized blood clots of the bladder.

\section{Introduction}

Although photoselective vaporization of the prostate (PVP) and holmium laser enucleation of the prostate (HoLEP) have been shown to have significantly less blood loss and are less likely to require transfusion than transurethral resection of the prostate (TURP) and open simple prostatectomy, these techniques are not without bleeding complications. ${ }^{1-7}$ Blood clots within the bladder postoperatively can be removed by a number of methods, including hand irrigation through a Foley catheter or cystoscopic evacuation with an evacuation device. ${ }^{8-10}$ Large, organized blood clots within the bladder causing urinary retention that are refractory to these classic management techniques pose a significant challenge to the surgeon.

Herein, we demonstrates a novel method for evacuating organized bladder clots causing urinary retention using a prostate morcellation device (PMD) after laser prostate surgery for benign prostatic hyperplasia $(\mathrm{BPH})$. The safety and effectiveness of the use of a PMD to evacuate organized bladder blood clot is demonstrated.

\section{Methods}

\section{Patients}

Following institutional review board approval, six patients included in this series underwent bladder clot evacuation using a PMD between August 2015 and April 2016, five patients post-HoLEP and one post-PVP. The overall rate of clot retention following the aforementioned procedures was $1.74 \%$.

\section{Equipment setup}

The setup used is similar to the one used for HoLEP, which consists of a $28 \mathrm{Fr}$ laser resectoscope and sheath (Karl Storz, Tuttlingen, Germany) and a 100 watt holmium laser (Lumenis, Inc. Yokneam, Israel), which was used to achieve hemostasis. A 26 Fr offset nephroscope (Karl Storz, Tuttlingen, Germany) and a Wolf Piranha rotatory PMD (Richard Wolf, Knittlingen, Germany) was used to morcellate the organized clot. A double irrigation system employing a Y-tubing connector and a single continuous bladder irrigation tube was used to distend the bladder during the morcellation process. The rotary morcellator blade, tissue collector tank, motor handle, generator, suction pump, and tube set are all disposable. Finally, there is a dual-function foot switch with separate pedals for morcellation and suction, which improves safety.

Fig. 1 shows the setup for the morcellation of bladder blood clots using a PMD. 


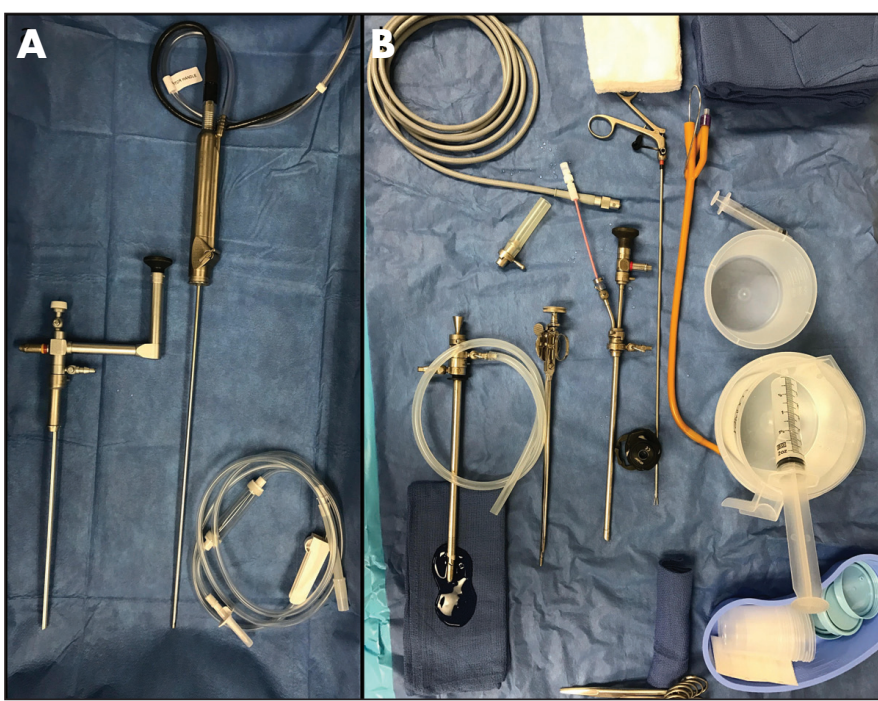

Fig. 1. Surgical setup and equipment: $(\boldsymbol{A})$ the Storz nephroscope and prostate morcellator device parts; and (B) the Storz laser resectoscope.

\section{Morcellator description}

Fig. 2 shows the morcellator device and its parts. The morcellator device used for procedures in this study, the Richard Wolf Piranha PMD, has a rotating morcellator blade that moves side to side, accessing tissue via a small window on the side of the instrument (Fig. 2B). The tip of the morcellator is blunt and does not move, which is ideal for safety. Different designs had reciprocating blades, which moved tissue back and forth during morcellation and created the potential for accidental tissue injury. The morcellator has two modes: suction only and combined suction-morcellation, controlled via the foot pedal. The Richard Wolf PMD has been shown to effectively cut up to $18 \mathrm{~g}$ of tissue per minute. ${ }^{11}$

\section{Morcellation technique}

Prior to cystoscopy with blood clot evacuation, all patients exhibited signs and symptoms of clot urinary retention after Foley catheter removal. After appropriate informed consent and a procedural time-out per institutional standards, cystoscopy was performed. Patients were put under general anesthesia using a laryngeal mask airway (LMA) in five patients and an endotracheal tube (ET) in one patient. The patients were placed in a dorsal lithotomy position. A 26 Fr Storz laser resectoscope (Karl Storz, Tuttlingen, Germany) with a 30-degree lens was introduced into the bladder. The bladder was then inspected completely to identify blood clots, sources of bleeding, and any other abnormalities of the bladder, prostatic urethra, or ureteral orifices. Bleeding within the prostatic fossa was managed at this point using either electrocautery or holmium laser with a setting of 40 watts (2 joules and $20 \mathrm{~Hz}$ ) until hemostasis. This step is critical for

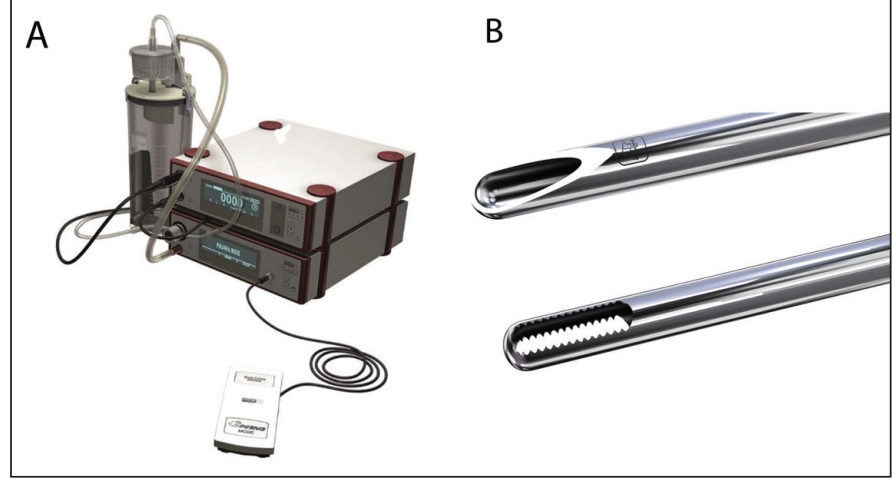

Fig. 2. Wolf Piranha prostate morcellator device safety features: $(\boldsymbol{A})$ the device has separate pedals for suction and morcellation for added safety; and (B) Wolf Piranha prostate morcellator device blades demonstrating the blunt end and rotating blades for improved safety.

achieving a clear field of view, which is very important for safe morcellation. Next, an Ellik evacuator (Bard Medical, Murray Hill, NJ, U.S.) was used to attempt to evacuate clot from the bladder and prostatic fossa. If blood clots were too big to be removed or were adherent to the prostatic fossa, they was displaced with the Ellik evacuator. When these attempts failed, the laser resectoscope was exchanged for the Storz 26 Fr offset nephroscope and, under dual irrigation, the Wolf Piranha PMD was introduced. The PMD was used to suck and evacuate the remaining blood clot within the bladder and prostate fossa under direct vision (Fig. 3). Upon failure of suction only mode, morcellation was performed as long as necessary to remove the clot in the bladder lumen. The clot size was estimated by weighing the contents of the morcellator trapper using a scale. The bladder was emptied and the cystoscope was removed. Following the procedure, catheters were removed when patients were able to urinate without recurrence of obstructive symptoms.

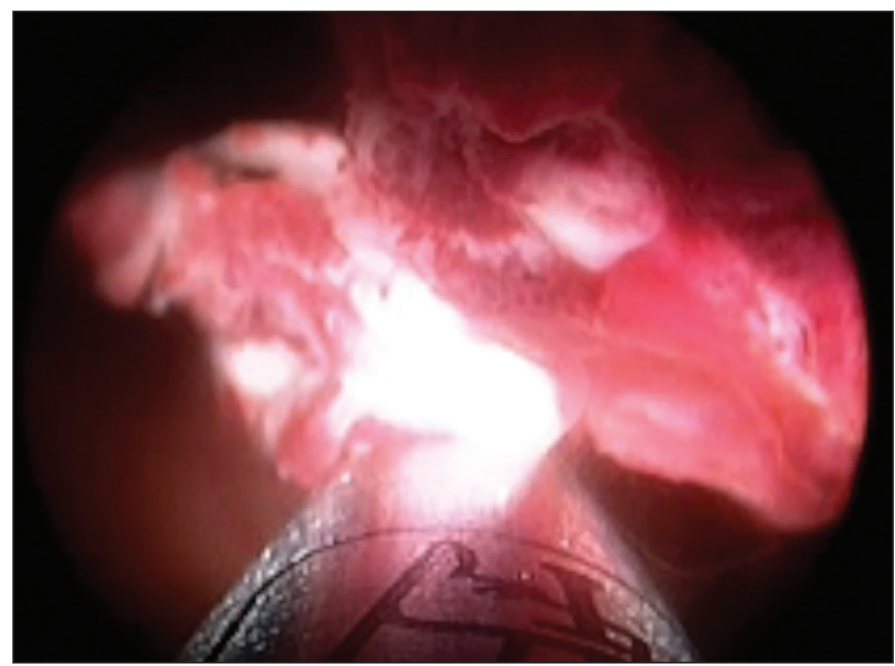

Fig. 3. Morcellation of the clot. 


\section{Statistical analysis}

Statistics were performed using Prism (GraphPad) and included means with standard deviations, medians with ranges if the data was non-normal, and student's t-tests. Statistics are notated as means \pm standard deviation.

\section{Results}

\section{Patients}

Between August 2015 and October 2016, 340 patients underwent TURP, with 220 patients receiving HoLEPs and 120 receiving PVPs. Of these patients, six (1.74\%) had clot urinary retention, failed conservative management, and eventually required clot removal with a PMD. Management techniques prior to PMD included irrigation through a $24 \mathrm{Fr}$ three-way Foley catheter and continuous bladder irrigation. Patient characteristics are summarized in Table 1. All patients were male with a mean age of $75 \pm 8.9$ years. The etiology of clot urinary retention was due to laser prostate surgery; five patients had a prior HoLEP and one patient had a prior PVP. Presenting symptoms included urinary retention and hematuria. Bladder blood clots were recognized a median of 3.5 days following prostatectomy procedure with a range of 1-19 days.

\section{Outcomes}

Outcomes are summarized in Table 2. In all six patients, clot evacuation with the Ellik evacuator was attempted and failed prior to the use of the Wolf Piranha PMD for clot evacuation. In four of six patients, holmium laser was used to establish

\begin{tabular}{lc}
\hline \multicolumn{2}{l}{ Table 1. Patient and procedure characteristics } \\
\hline Parameter & Value \\
\hline Number of patients & 6 \\
Age, mean (SD) & $75(8.9)$ \\
Sex & Male $(n=6)$ \\
Reason for clot & Status post-prostatectomy ( $n=6)$ \\
Prostatectomy type & HoLEP, $n=5 ;$ laser, $n=1$ \\
Prostate specimen diagnosis & $B P H(n=6)$ \\
Prostate size in cc, mean (SD) & $41(12)(n=6)$ \\
Anesthesia type & General, $n=6 ;$ LMA, $n=5 ; E T, n=1$ \\
$\begin{array}{l}\text { Procedure length in minutes, } \\
\text { mean (SD) }\end{array}$ & $52(12)(n=6)$ \\
$\begin{array}{l}\text { Cystoscope } \\
\text { Morcellator }\end{array}$ & Storz offset resectoscope $(n=6)$ \\
Morcellator time in minutes, & Wolf Piranha morcellator $(n=6)$ \\
mean (SD) & $10.2(6.15)(n=6)$ \\
\hline $\begin{array}{l}\text { BPH: benign prostatic hyperplasia; ET: endotracheal tube; HoLEP: holmium laser } \\
\text { enucleation of the prostate; LMA: laryngeal mask airway SD: standard deviation. }\end{array}$ \\
\hline
\end{tabular}

hemostasis and in the remaining two, electrocautery was used. Morcellator was used for an average of $10.2 \pm 6.15$ minutes in order to remove each patient's clot burden. Clot sizes were measured in all six patients and the clots were $173.3 \pm 115.9$ cc. Patients' catheters were removed a median of two days after the clot evacuation (range 1-12). The PMD successfully evacuated and sucked all of the clot refractory to the Ellik evacuator in all six patients under direct vision (Fig. 4).

\section{Tolerability of procedure}

The PMD was successful in the evacuation of the blood clots in $100 \%$ of the patients. No patients had bladder injuries or other complications related to use of the PMD.

\section{Discussion}

Large, organized clot within the bladder poses significant management challenges when classic endoscopic management techniques fail. Here we present the use of a PMD as an effective and safe update to the treatment algorithm for management of clot urinary retention after laser prostate surgery for $\mathrm{BPH}$. When bladder blood clots are sufficiently organized, they are not malleable enough to be suctioned using typical instruments such as a Toomey syringe or an Ellik evacuator. Disintegration of these clots is needed to maintain an endoscopic approach in these cases and a PMD is a useful instrument for this type of procedure. The Wolf Piranha PMD can be employed to target and evacuate clots under direct visualization, an advantage not afforded by other endoscopic techniques. The dual irrigation inflow and intermittent controlled suction outflow afforded by this technique allows for excellent visualization. It is important during the procedure not to morcellate when the field of

\begin{tabular}{lc}
\hline Table 2. Results & \\
\hline Parameter & Value \\
\hline Time to clot recognition in days, & $3.5(1-19)(\mathrm{n}=6)$ \\
median (range) & Ellik evacuator $(\mathrm{n}=6)$ \\
Device tried prior to morcellator & $4 / 6$ patients \\
Laser used & $2 / 6$ patients \\
Electrocautery used & $6 / 6$ patients \\
Organized clot & $60(20-200)(\mathrm{n}=4)$ \\
Clot size in cc, median (range) & $6 / 6$ patients \\
Clot successfully evacuated & None \\
Complications during clot & $2(1-12)$ \\
evacuation & Anemia requiring transfusion \\
Days with catheter post-clot & $(\mathrm{n}=2)$, clot recurrence \\
evacuation, median (range) & requiring rehospitalization and \\
& re-evacuation ( $\mathrm{n}=1)$ \\
Post-procedure complications &
\end{tabular}




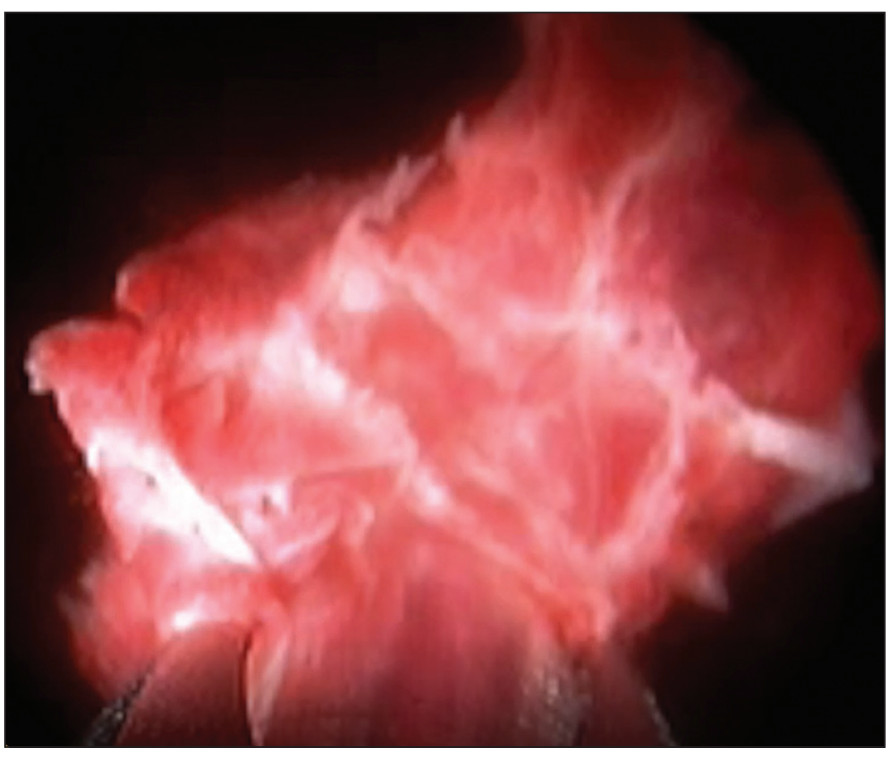

Fig. 4. Suction of blood clot under direct clear field of vision.

view is obscured by blood because this increases the risk of damage to the bladder wall. Hemostasis and a clear field of view must be achieved prior to attempting clot morcellation. The Wolf Piranha PMD has two separate pedals, one for suction alone and the other for a combination of morcellation and suction, which allows the operator to safely secure the clot, move into the bladder lumen, and then morcellate away from any surrounding structures, which limits the risk of unintended injury.

Outcomes in this study were encouraging, with no morcellator-related complications. No patients had bladder rupture or perforation during morcellation. Limitations of this study include its small size and lack of control group. A larger study observing outcomes across multiple centres is warranted, given the good outcomes in this study. Additionally, a randomized trial using another method of organized clot management vs. PMD is warranted. We recommend that this technique should not be used for clot retention cases caused by bladder tumours or bleeding of undiagnosed etiology.

\section{Conclusion}

In this study of six patients with clot urinary retention, five post HoLEP and one post PVP, who previously failed stan- dard clot evacuation techniques, morcellation of the bladder blood clots using a PMD was successful in removing the entire residual clot burden in $100 \%$ of patients. No PMDrelated complications were encountered. Thus, use of a Wolf Piranha PMD for evacuation of organized bladder blood clots is safe and effective and warrants further study with a larger patient cohort.

Competing interests: The authors report no competing personal or financial interests.

This paper has been peer-reviewed.

\section{References}

1. Gupta N, Sivaramakrishna, KR, Dogra PN, et al. Comparison of standard transurethral resection, transurethral vapour resection and holmium laser enucleation of the prostate for managing benign prostatic hyperplasia of >40 g. BJU Int 2006;97:85-9. https://doi.org/10.1111/i.1464-410X.2006.05862.x

2. Kuntz RM, Ahyai $S$, Lehrich $K$, et al. Transurethral holmium laser enucleation of the prostate vs. transurethral electrocautery resection of the prostate: A randomized, prospective trial in 200 patients. J Urol 2004;72:1012-6. https://doi.org/10.1097/01.ju.0000136218.11998.9e

3. Kuntz RM, Lehrich K. Transurethral holmium laser enucleation vs. transvesical open enucleation for prostate adenoma greater than $100 \mathrm{~g}$ : A randomized prospective trial of 120 patients. J Urol 2002;168:1465-9. https://doi.org/10.1016/50022-5347(05)64475-8

4. Yin L, Teng J, Huang $\mathrm{CJ}$, et al. Holmium laser enucleation of the prostate vs. transurethral resection of the prostate: A systematic review and meta-analysis of randomized, controlled trials. J Endourol 2013;27:60411. https://doi.org/10.1089/end.2012.0505

5. Bouchier-Hayes DM. Photoselective vaporization of the prostate-towards a new standard. Prostate Cancer Prostatic Dis 2007:S10-4. https://doi.org/10.1038/si.pcan.4500951

6. Horasanli K, Silay MS, Altay B, et al. Photoselective potassium titanyl phosphate (KTP) laser vaporization vs. transurethral resection of the prostate for prostates larger than $70 \mathrm{~mL}$ : A short-term, prospective, randomized trial. Urology 2008:71:247-51. https://doi.org/10.1016/i.urology.2007.09.017

7. Alivizatos $G$, Skolarikos $A$, Chalikopoulos $D$, et al. Transurethral photoselective vaporization vs. transvesical open enucleation for prostatic adenomas $>80 \mathrm{ml}$ : 12-month results of a randomized, prospective study. Eur Urol 2008:54:427-37. htrps://doi.org/10.1016/i.eururo.2007.11.044

8. Davis TM. A Simple method for removing blood clots from the urinary bladder. JAMA 1929;92:2168. https://doi.org/10.1001/jama.1929.92700520001007

9. Goel A, Sengottayan VK, Dwivedi AK. Mechanical suction: A safe and effective method to remove large and tenacious clots from the urinary bladder. Urology 2011;7:494-6. https://doi.org/10.1016/i. urology.2010.09.035

10. Yu HS, Ham WS, Hah TS, et al. Simple, safe, and successful evacuation of severe organized clot retention using a catheter connected with wall suction: Suction and fishing method. Urology 2011:78:1199-202. https://doi.org/10.1016/i.urology.2011.07.1390

11. El Tayeb MM, Borofsky MS, Paonessa JE, et al. Wolf Piranha vs. Lumenis VersaCut prostate morcellation devices: A prospective, randomized trial. J Urol 2016:195:413-7.

Correspondence: Dr. Marawan M. El Tayeb, Baylor Scott and White Health, Temple, TX, United States; Marawan.EITayeb@bswhealth.org 